\title{
Double Lumen Endotracheal Tube for Percutaneous Tracheostomy
}

\author{
Maria Vargas MD, Giuseppe Servillo MD, Gaetano Tessitore MD, Fulvio Aloj MD, \\ Iole Brunetti MD, Enrico Arditi MD, Dorino Salami MD, \\ Robert M Kacmarek PhD RRT FAARC, and Paolo Pelosi MD
}

\begin{abstract}
BACKGROUND: Percutaneous dilational tracheostomy is normally a bronchoscope-guided procedure. The insertion of a bronchoscope into an endotracheal tube (ETT) affects resistance, flow, and alveolar pressure. To improve airway management and ventilation during percutaneous tracheostomy, we developed a double lumen endotracheal tube (DLET). The aim of this in vitro study was to compare the linear constant of the Rohrer equation $\left(K_{1}\right)$, the nonlinear constant of the Rohrer equation $\left(\mathrm{K}_{2}\right)$, the inspiratory and expiratory airway resistance, and ventilatory and airway pressures using the DLET with different standard sized ETTs. METHODS: A trachea and lung model was used to compare the DLET to ETTs with 7, 7.5, and $8 \mathrm{~mm}$ inner diameters with and without a bronchoscope ( $4.5 \mathrm{~mm}$ external diameter), and 4 and $5 \mathrm{~mm}$ inner diameter ventilation tubes $\left(F_{4}, F_{5}\right)$ of a translaryngeal tracheostomy. For each device, the pressure drop across the device and the Rohrer equation linear constant $\left(K_{1}\right)$ and nonlinear constant $\left(K_{2}\right)$ were calculated during a continuous flow of $10-90 \mathrm{~L} / \mathrm{min}$, the inspiratory and expiratory airway resistance values were calculated during volume controlled mechanical ventilation, and respiratory airway pressure values were calculated during volume and pressure controlled mechanical ventilation. RESULTS: DLET had lower $K_{2}$, pressure drop, and inspiratory and expiratory airway resistance compared with conventional ETTs plus fiberoptic bronchoscope. Furthermore, during mechanical ventilation, DLET had a lower value of peak pressure, mean pressure, and intrinsic PEEP than the other ETTs plus fiberoptic bronchoscope. CONCLUSIONS: Use of the DLET during percutaneous dilational tracheostomy allows fiberoptic bronchoscopy without imposing excessive airway resistance. Reduced tube resistance during this procedure may confer additional safety in what is well known to be a hazardous procedure. Key words: tracheostomy; double lumen endotracheal tube; airway management; intensive care. [Respir Care 2014;59(11):1652-1659. (C) 2014 Daedalus Enterprises]
\end{abstract}

\section{Introduction}

Percutaneous dilational tracheostomy (PDT) is widely used in ICUs. ${ }^{1}$ Various PDT techniques have been pro-

\footnotetext{
Drs Vargas, Servillo, and Tessitore are affiliated with the Department of Neuroscience and Reproductive and Odontostomatological Sciences, University of Naples "Federico II," Naples, Italy; Dr Aloj is affiliated with the Anaesthesia and Intensive Care Unit, Istituto di Ricovero e Cura a Carattere Scientifico Neuromed, Pozzilli, Italy; Drs Brunetti, Arditi, and Salami are affiliated with the Department of Anesthesia and Intensive Care, Istituto di Ricovero e Cura a Carattere Scientifico, Azienda Ospedaliera Universitaria San Martino IST, University of Genoa, Genoa, Italy; Dr Kacmarek is affiliated with the Department of Anesthesiology and Critical Care and the Department of Respiratory Care, Massachusetts General Hospital, Boston, Massachusetts; Dr Pelosi is affiliated with the Department of Surgical and Integrated Sciences and the Department
}

posed, differing primarily based on the device used for stoma dilation. However, during PDT, the patients' airway has been normally managed by a single lumen endotra-

\footnotetext{
Anesthesia and Intensive Care, Istituto di Ricovero e Cura a Carattere Scientifico, Azienda Ospedaliera Universitaria San Martino IST, University of Genoa, Genoa, Italy.

Dr Kacmarek discloses relationships with Covidien and Maquet. The other authors have disclosed no conflicts of interest.

Correspondence: Maria Vargas MD, Department of Neuroscience and Reproductive and Odontostomatological Sciences, University of Naples "Federico II," via Pansini 16, 80100 Naples, Italy. E-mail: vargas. maria82@gmail.com.
}

DOI: $10.4187 /$ respcare. 03161 


\section{Double Lumen Endotracheal Tubes for PDT}

cheal tube (ETT). ${ }^{1}$ All PDT methods include bronchoscope-guided tracheal puncture, allowing visualization of the tracheal lumen. ${ }^{2}$ This has improved localization of the insertion site, safety, and avoidance of possible injury to the posterior wall of the trachea during the procedure. However, the placement of a bronchoscope through the ETT during tracheostomy may be associated with procedural and ventilation problems. When a bronchoscope is inserted through an ETT, it affects resistance, flow, and alveolar pressure. ${ }^{3}$

To improve airway management and ventilation of patients during percutaneous tracheostomy, we developed a double lumen endotracheal tube (DLET), which allows bronchoscopy without compromising ventilation. Furthermore, the DLET may have advantages regarding patients' safety and comfort over the standard ETT during bronchoscopy.

The aim of this in vitro study was to compare the linear constant of the Rohrer equation $\left(\mathrm{K}_{1}\right)$, the nonlinear constant of the Rohrer equation $\left(\mathrm{K}_{2}\right)$, the inspiratory and expiratory airway resistance, and ventilatory and airway pressures using the DLET with different standard sized ETTs.

\section{Methods}

\section{Double Lumen Endotracheal Tube}

The DLET (bilumen ventilation tube, Deas, Castel Bolognese, Italy; international patent application PCT/IT2012/ 000154) designed for PDT is divided into an upper channel, for placement of a fiberoptic bronchoscope, and a lower channel, exclusively dedicated to the patient's ventilation (Fig. 1). The upper lumen has a length of $18.8 \mathrm{~cm}$ and an internal diameter of $9 \mathrm{~mm}$. The lower lumen has a length of $29 \mathrm{~cm}$, an inner diameter of $7.5 \mathrm{~mm}$ (crosssectional area $44.1 \mathrm{~mm}^{2}$ ), and an asymmetric distal cuff positioned just above the carina. The lower lumen assumes an elliptical shape from the vocal cord level to the distal tip. The distance between the end of the upper channel and the distal cuff of the DLET is $7.5 \mathrm{~cm}$, according to the inner diameter of lower lumen $(7.5 \mathrm{~mm})$. At the vocal cord level, the DLET has an external diameter of $8 \mathrm{~mm}$ because of the size of the lower lumen.

\section{Experimental Set-Up}

To calculate the linear constant of the Rohrer equation $\left(\mathrm{K}_{1}\right)$, the nonlinear constant of the Rohrer equation $\left(\mathrm{K}_{2}\right)$, and pressure drop for each ETT, we used an experimental model with a continuous flow. Flow of $10-90 \mathrm{~L} / \mathrm{min}$ was used with $10 \mathrm{~L} / \mathrm{min}$ progressive increments. The continuous flow was provided by a flow meter connected to a pneumotachograph (Fleisch No. 2) and a pressure transducer (KT 1D-2, Kleistek, Bari, Italy) immediately placed

\section{QUICK LOOK}

\section{Current knowledge}

Percutaneous tracheostomy is normally a bronchoscopeguided procedure. The insertion of the bronchoscope into an endotracheal tube affects resistance, flow, alveolar pressure, and minute ventilation.

\section{What this paper contributes to our knowledge}

The use of a double lumen endotracheal tube during percutaneous tracheostomy allows fiberoptic bronchoscopy without imposing excessive airway resistance in a model. Reduced tube resistance during this procedure may prevent high airway pressures and preserve minute ventilation.

at the proximal end of each ETT. The pneumotachograph was connected to a pressure box containing a 16-bit analog-to-digital converter that converts the electrical signals acquired by the transducer in digital signals and stored to a personal computer. The distal end of each ETT was unobstructed and open to the atmosphere.

To calculate the inspiratory and expiratory airway resistance and ventilator and airway pressure, an experimental lung model as shown in Figure 2 was used.

One bellow with a total compliance of $33 \mathrm{~cm} \mathrm{H}_{2} \mathrm{O} \mathrm{L}^{-1}$ was used to simulate lungs with an artificial trachea consisting of a transparent tube of $21 \mathrm{~mm}$ inner diameter. The ETT under investigation were introduced into the artificial

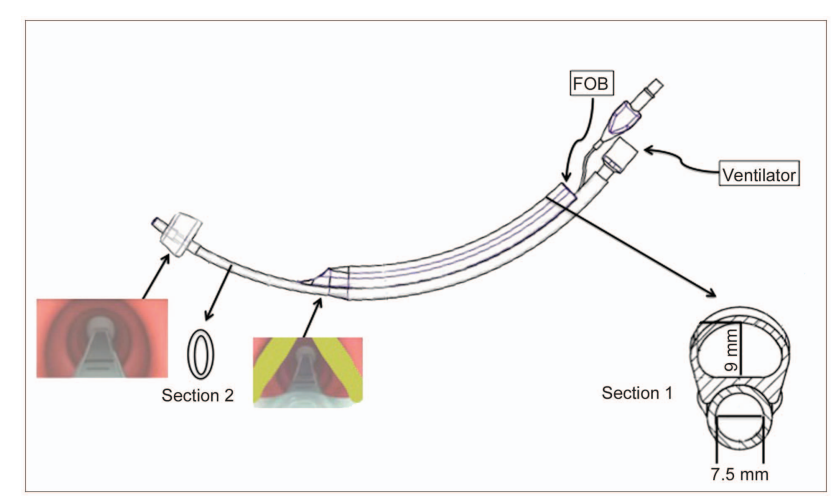

Fig. 1. Double lumen endotracheal tube (DLET) with its upper channel dedicated to fiberoptic bronchoscopy (FOB) and lower channel exclusively dedicated to ventilation. The end of the upper lumen should be positioned at the vocal cord level. From this point to the distal end, the lower lumen has an elliptical shape. The asymmetrical distal cuff should be positioned just above the carina. Section 1: Proximal section of DLET. The upper lumen has an internal diameter of $9 \mathrm{~mm}$, whereas the lower one has an internal diameter of $7.5 \mathrm{~mm}$. Section 2: Distal section of the DLET showing the lower lumen's elliptical shape. 


\section{Double Lumen Endotracheal Tubes for PDT}

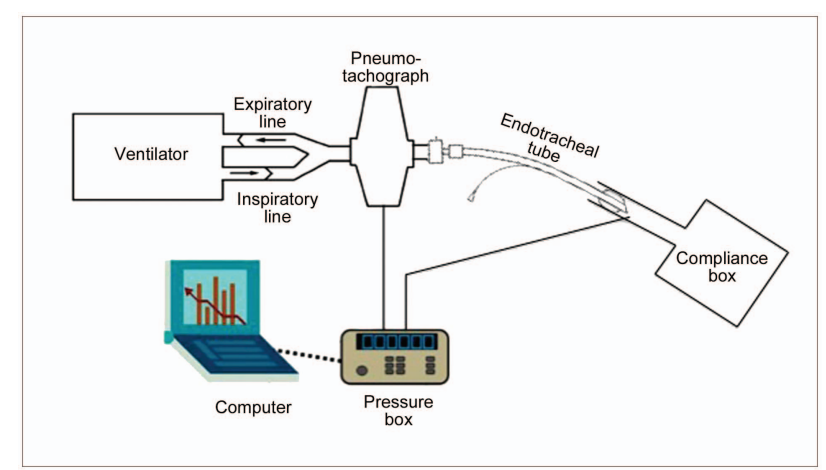

Fig. 2. The experimental in vitro lung model used to test different endotracheal and tracheostomy tubes. Further details on the physical layout of the lung model are described in text.

trachea. The proximal end of the ETT was connected to a mechanical ventilator (Evita Infinity V500, Draeger Medical, Telford, Pennsylvania), and the cuff of each ETT was insufflated in the artificial trachea. Flow and proximal ETT pressure were measured by a pneumotachograph (Fleisch No. 2) and a pressure transducer (KT 1D-2, Kleistek). Distal ETT pressure was measured with a thin catheter positioned $6 \mathrm{~mm}$ from the tip of the ETT. The pneumotachograph and the distal catheter were connected to a pressure box containing a 16-bit analog-to-digital converter that converts the electrical signals acquired by the transducer to digital signals. All data were then stored on a personal computer.

All data were collected using ICU-Lab software (Kleistek). Because this was an in vitro study, no approval from the local institutional review board was required.

\section{Protocol}

The ETTs investigated were 7, 7.5, and $8 \mathrm{~mm}$ inner diameter; 7, 7.5, and $8 \mathrm{~mm}$ inner diameter ETTs with $4.5 \mathrm{~mm}$ external diameter bronchoscope inserted into the ETT (7f, 7.5f, and 8f); 4 and $5 \mathrm{~mm}$ inner diameter ventilation tubes $\left(\mathrm{F}_{4}\right.$ and $\left.\mathrm{F}_{5}\right)$ of a translaryngeal tracheostomy (Mallinckrodt, St Louis, Missouri), and the DLET with a lower lumen of $7.5 \mathrm{~mm}$ inner diameter. DLET was tested with the fiberoptic bronchoscope in the upper channel. Table 1 shows the characteristics of ETT and DLET under investigation.

For each ETT evaluated in this study, the pressure drop across the ETT, the linear constant of the Rohrer equation $\left(\mathrm{K}_{1}\right)$, and the nonlinear constant of the Rohrer equation $\left(\mathrm{K}_{2}\right)$ were calculated during a continuous flow, progressively increased from 10 to $90 \mathrm{~L} / \mathrm{min}$.

The pressure drop across each ETT was taken as the difference between the pressure at the entrance of the endotracheal tube and atmospheric pressure. For each flow, a 1-min recording was started at the achievement of steady state gas flow. The pressure drop was calculated offline for each $2 \mathrm{~s}$ of recorded trace.

The linear constant $\left(\mathrm{K}_{1}\right)$ and the nonlinear constant $\left(\mathrm{K}_{2}\right)$ were calculated using the following Rohrer equation ${ }^{4}$ :

$$
\Delta \mathrm{P}_{\mathrm{ETT}}=\mathrm{K}_{1} \mathrm{~F}+\mathrm{K}_{2} \mathrm{VF}^{2}
$$

This equation describes the resistive property of each ETT; it combines linear and nonlinear pressure flow $(\mathrm{F})$ dependence. ${ }^{5} \mathrm{~K}_{1}$ and $\mathrm{K}_{2}$ coefficients were determined by fitting Equation 1 to the measured pressure drop and flow values using the least-squares method. 6,7

Airway resistance was calculated for each ETT during the inspiratory and expiratory phase of volume controlled continuous mandatory ventilation (VC-CMV) with a squarewave flow pattern. Airway resistance was calculated as pressure drop/flow across each ETT. VC-CMV was set with a tidal volume of $500 \mathrm{~mL}$, PEEP $5 \mathrm{~cm} \mathrm{H}_{2} \mathrm{O}$, inspiratory:expiratory ratio $1: 2$, and breathing frequency 15 breaths/min.

Ventilator and airway pressures, peak pressure $\left(\mathrm{P}_{\text {peak }}\right)$, mean pressure $\left(\mathrm{P}_{\text {mean }}\right)$, and intrinsic PEEP (PEEPi), were determined during volume and pressure controlled continuous mandatory ventilation (PC-CMV) with the same settings as above. During PC-CMV, the inspiratory pressure was modified to reach a stable tidal volume of $500 \mathrm{~mL}$.

When a steady-state condition was reached, 2 respiratory cycles for each ventilation setting were recorded to determine inspiratory and expiratory airway resistance, $\mathrm{P}_{\text {peak }}, \mathrm{P}_{\text {mean }}$, and flow. PEEPi was measured during a third and a fourth ventilatory cycle with a 2-s expiratory hold maneuver in each cycle.

Data from all trials were recorded online and analyzed offline with ICU-Lab software (Kleistek). This software allows us to collect and analyze data for every single mechanical breath. Each ETT was tested first with continuous flow, then with VC-CMV and PC-CMV without blinding to the experimental condition.

\section{Statistical Analysis}

Data were reported as median and interquartile range. Normal distribution was evaluated with the Shapiro-Wilk normality test. Wilcoxon signed-rank test was used to assess differences in the distribution of pressure drops during continuous flow. For each ETT, the constants of the Rohrer equation $\left(\mathrm{K}_{1}\right.$ and $\left.\mathrm{K}_{2}\right)$ were calculated by plotting the pressure drop with flow using linear regression analysis and the least-squares method. Then, we calculated the CI to compare the slopes of these plots and the goodness of fit $\left(\mathrm{r}^{2}\right)$ to evaluate the strength of association between variables. Differences between data acquired during mechanical ventilation were assessed with Kruskal-Wallis 
Table 1. Characteristics of Different ETTs and Tracheostomy Tubes Involved in the Study

\begin{tabular}{|c|c|c|c|c|c|c|c|c|c|}
\hline & \multicolumn{9}{|c|}{ ETT/Tracheostomy Tubes } \\
\hline & 7 & 7.5 & 8 & $7 f$ & $7.5 \mathrm{f}$ & $8 \mathrm{f}$ & $\mathrm{F}_{4}$ & $\mathrm{~F}_{5}$ & DLET \\
\hline Length (cm) & 32 & 32 & 32 & 32 & 32 & 32 & 40 & 40 & $\begin{array}{l}29 \text { (lower lumen) } \\
18.8 \text { (upper lumen) }\end{array}$ \\
\hline Cross-sectional diameter (mm) & 7 & 7.5 & 8 & 2.5 & 3 & 3.5 & 4 & 5 & $\begin{array}{l}7.5 \text { (lower lumen) } \\
9 \text { (upper lumen) }\end{array}$ \\
\hline Cross-sectional area $\left(\mathrm{mm}^{2}\right)$ & 38.4 & 44.1 & 50.2 & 22.6 & 28.3 & 34.3 & 12.5 & 19.6 & 44.1 \\
\hline Total surface area $\left(\mathrm{mm}^{2}\right)$ & 730 & 841 & 904 & 133 & 245 & 307 & 527.5 & 667 & 842 \\
\hline $\begin{array}{l}\text { Cross-sectional area was calculated accord } \\
\text { ETT }=\text { endotracheal tube } \\
7,7.5 \text {, and } 8=7,7.5 \text {, and } 8 \mathrm{~mm} \text { inner dia } \\
7 f, 7.5 f \text {, and } 8 \mathrm{f}=7,7.5 \text {, and } 8 \mathrm{~mm} \text { inner } \\
\mathrm{F}_{4} \text { and } \mathrm{F}_{5}=4 \text { and } 5 \mathrm{~mm} \text { inner diameter v } \\
\text { DLET }=\text { double lumen endotracheal tube }\end{array}$ & $\begin{array}{l}\text { geomet } \\
\text { endotrac } \\
\text { tion tubes }\end{array}$ & $\begin{array}{l}\text { definition c } \\
\text { ubes } \\
\text { a tubes wi } \\
\text { translaryng }\end{array}$ & $\begin{array}{l}\text { mm exter } \\
\text { racheostom }\end{array}$ & iameter fib & c broncho & inserted $\mathrm{i}$ & e endotrac & tube & \\
\hline
\end{tabular}

nonparametric test. When analysis of variance revealed a significant difference, paired comparison test to identify the difference for each pair was performed using the MannWhitney nonparametric test, and $P$ value was adjusted with the Bonferroni correction. $P<.05$ was considered significant. Statistical analysis was performed with SPSS 20.0 (SPSS, Chicago, Illinois).

\section{Results}

\section{Pressure Drop and Rohrer Linear Constant}

Figure 3 shows the pressure drop across each ETT as continuous flow increased from 10 to $90 \mathrm{~L} / \mathrm{min}$. The DLET had a pressure drop higher than ETT 7, 7.5, and 8 without fiberoptic bronchoscope, but lower than ETTs 7f, 7.5f, 8f, $\mathrm{F}_{4}$, and $\mathrm{F}_{5}$. All comparisons were statistically significant except DLET versus 7 (DLET vs $7 P=.51$; DLET vs 7.5 $P=.02$; DLET vs $8 P=.01$; DLET vs 7 f $P=.008$; DLET vs $7.5 \mathrm{f} P=.008$; DLET vs $8 \mathrm{f} P=.008$; DLET vs $\mathrm{F}_{4} P=.03$; DLET vs $\mathrm{F}_{5} P=.01$ ).

Table 2 shows the constants of the Rohrer equation $\left(\mathrm{K}_{1}\right.$ and $\mathrm{K}_{2}$ ) calculated for each ETT. DLET had the lowest $\mathrm{K}_{2}$; furthermore, the results for all ETT had an excellent coefficient of determination $\left(\mathrm{r}^{2}>0.9\right)$.

\section{Inspiratory and Expiratory Airway Resistance}

Figure 4 shows the airway resistance measured during VC-CMV. The inspiratory and expiratory airway resistance for the DLET was lower than 7f, 7.5f, 8f, $F_{4}$, and $F_{5}$ but higher than ETTs $7,7.5$, and 8 without fiberoptic bronchoscope. Statistical significance was $P=.001$ for all comparisons of inspiratory phase and $P=.002$ for all comparisons of expiratory phase.

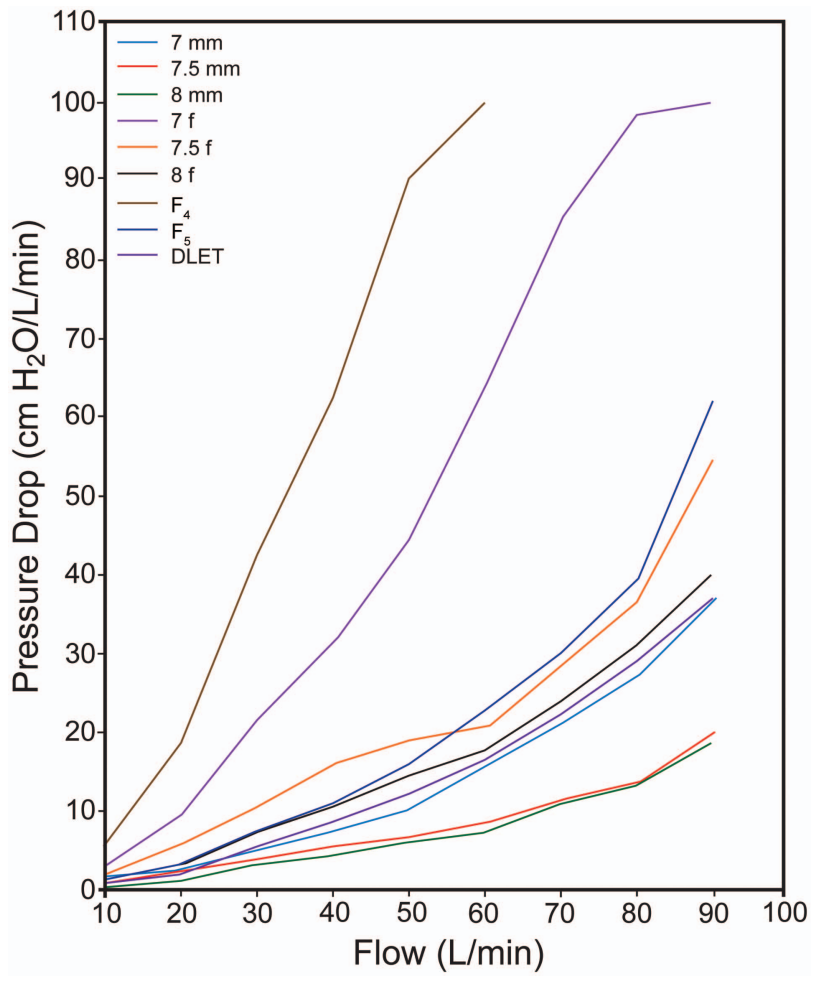

Fig. 3. Pressure drop across different endotracheal tubes (ETTs) during continuous flow. Tubes denoted with $\mathrm{mm}$ refer to the tube's inner diameter measurement; tubes denoted with $f$ refer to tubes with a $4.5 \mathrm{~mm}$ external diameter fiberoptic bronchoscopy tube inserted; $F_{4}$ and $F_{5}$ refer to 4 and $5 \mathrm{~mm}$ inner diameter ventilation tubes, respectively; DLET refers to double lumen ETT, with $7.5 \mathrm{~mm}$ inner diameter.

\section{Respiratory Airway Pressure}

Table 3 shows the ventilator and airway pressures measured during VC-CMV. The inspiratory $\mathrm{P}_{\text {peak }}$, expiratory $\mathrm{P}_{\text {peak }}, \mathrm{P}_{\text {mean }}$, and PEEPi during VC-CMV were lower with 
Table 2. Rohrer Constants $\left(\mathrm{K}_{1}\right.$ and $\left.\mathrm{K}_{2}\right)$ of Different ETTs and Tracheostomy Tubes

\begin{tabular}{|c|c|c|c|c|}
\hline \multirow{2}{*}{$\begin{array}{c}\text { ETT/Tracheostomy } \\
\text { Tube }\end{array}$} & \multicolumn{4}{|c|}{ Rohrer Constant Equation Values } \\
\hline & $\begin{array}{c}\mathrm{K}_{1} \\
\left(\mathrm{~cm} \mathrm{H}_{2} \mathrm{O} \mathrm{L}^{-1} \min ^{-1}\right)\end{array}$ & $\begin{array}{c}\mathrm{K}_{2} \\
\left(\mathrm{~cm} \mathrm{H}_{2} \mathrm{O} \mathrm{L}^{-1} \min ^{-1}\right)\end{array}$ & $\mathrm{K}_{2} \mathrm{CI}$ & $\begin{array}{c}\text { Goodness of Fit } \\
\left(\mathrm{r}^{2}\right)\end{array}$ \\
\hline 7 & 4.8 & 11.33 & 7.82 to 14.84 & $>0.99$ \\
\hline 7.5 & 2.89 & 8.74 & 6.72 to 10.76 & $>0.99$ \\
\hline 8 & 1.51 & 7.57 & 5.04 to 10.1 & 0.99 \\
\hline $7 f$ & 68.11 & 6.13 & -30.96 to -43.22 & 0.96 \\
\hline $7.5 f$ & 15.25 & 10.52 & 7.1 to 13.2 & $>0.99$ \\
\hline $8 \mathrm{f}$ & 8.95 & 12.28 & 8.08 to 16.47 & $>0.99$ \\
\hline $\mathrm{F}_{4}$ & -53.48 & 130.0 & -73.99 to -334.0 & 0.92 \\
\hline $\mathrm{F}_{5}$ & 16.75 & 11.12 & 6.77 to 15.48 & $>0.99$ \\
\hline DLET & 20.11 & 5.25 & -4.91 to 15.42 & 0.98 \\
\hline \multicolumn{5}{|c|}{$\begin{array}{l}\text { The } 95 \% \mathrm{CI} \text { is shown for } \mathrm{K}_{2} \text {, while the goodness of fit }\left(\mathrm{r}^{2}\right) \text { showed the strength of association between pressure drop and flow. } \\
\text { ETT }=\text { endotracheal tube } \\
7,7.5 \text {, and } 8=7,7.5 \text {, and } 8 \mathrm{~mm} \text { inner diameter endotracheal tubes } \\
7 f, 7.5 \mathrm{f} \text {, and } 8 \mathrm{f}=7,7.5 \text {, and } 8 \mathrm{~mm} \text { inner diameter endotracheal tubes with } 4.5 \mathrm{~mm} \text { external diameter fiberoptic bronchoscope inserted into the endotracheal tube } \\
\mathrm{F}_{4} \text { and } \mathrm{F}_{5}=4 \text { and } 5 \mathrm{~mm} \text { inner diameter ventilation tubes of a translaryngeal tracheostomy tubes } \\
\text { DLET }=\text { double lumen endotracheal tube }\end{array}$} \\
\hline
\end{tabular}

DLET compared with 7f, 7.5f, 8f, $\mathrm{F}_{4}$, and $\mathrm{F}_{5}(P<.05$ for all comparisons).

Table 4 shows the airway pressures measured during PC-CMV. The inspiratory $\mathrm{P}_{\text {peak }}$, expiratory $\mathrm{P}_{\text {peak }}, \mathrm{P}_{\text {mean }}$, and PEEPi during PC-CMV were lower with DLET compared with $7 \mathrm{f}, 7.5 \mathrm{f}, 8 \mathrm{f}, \mathrm{F}_{4}$, and $\mathrm{F}_{5}(P<.05$ for all comparisons).

\section{Discussion}

This is the first in vitro study assessing the physical properties of a DLET designed for use during percutaneous tracheostomy. Our primary finding can be summarized as follows: in a model airway for percutaneous tracheostomy, the DLET with fiberoptic bronchoscope has a lower $\mathrm{K}_{2}$ Rohrer constant during continuous flow and a lower resistance to gas flow during simulated mechanical ventilation, than other ETTs with a fiberoptic bronchoscope in place and translaryngeal airways.

Percutaneous tracheostomy as is currently performed in the ICU is not without risks. ${ }^{1}$ Different methods, such as laryngeal mask airways or pediatric airways, have been proposed to improve airway management, ventilation, and procedural comfort during PDT, minimizing complications such as hypoventilation and endoscopic interference. ${ }^{8} \mathrm{How}-$ ever, none of these techniques are ideal.

$\mathrm{K}_{2}$ is an indicator of the degree of patency and thus the magnitude of ETT obstruction. ${ }^{7}$ In our study, the DLET had a lower value for $\mathrm{K}_{2}$ than other devices commonly used for PDT, thus resulting in adequate airway patency and minimal obstruction. This specific characteristic of the DLET may be explained by several factors: (1) the inner diameter of the DLET is larger than the ETT with fiber- optic bronchoscope, and (2) inner diameter and cross-sectional area of the DLET were larger than $\mathrm{F}_{4}$ and $\mathrm{F}_{5}$ with a shorter length. Furthermore, the $\mathrm{K}_{2}$ of $\mathrm{F}_{4}$ was higher than any other airway devices used for PDT, and $\mathrm{F}_{4}$ could not be evaluated for flows $>60 \mathrm{~L} / \mathrm{min}$.

Pressure drop has been used to describe ETT resistance. ${ }^{9}$ In our study, the DLET also had a lower pressure drop than all ETTs with fiberoptic bronchoscope, thus ensuring a lower resistance to air flow. Furthermore, DLET had a pressure drop similar to a $7 \mathrm{~mm}$ inner diameter ETT without fiberoptic bronchoscope. Because pressure drop across a tube is a direct measurement of the change in pressure throughout the entire tube, ${ }^{9}$ we believe that pressure drop across the DLET was similar to a $7 \mathrm{~mm}$ inner diameter ETT, as opposed to a $7.5 \mathrm{~mm}$ inner diameter ETT, because of (1) the elliptical shape of its distal section and (2) the minimal compression exerted by the fiberoptic bronchoscope on the lower channel.

During PDT, the presence of a bronchoscope reduces the ETT diameter available for patients' ventilation. ETT diameter is a critical factor determining airway resistance. ${ }^{9}$ The presence of a bronchoscope in the ETT further reduces the cross-sectional area, causing a partial obstruction to inspiratory and expiratory flow. ${ }^{10}$ In our experimental setting, the cross-sectional areas of ETTs with fiberoptic bronchoscope was reduced by $82 \%$ for 7 f, $71 \%$ for $7.5 \mathrm{f}$, and $66 \%$ for $8 \mathrm{f}$, whereas the cross-sectional area of DLET remained stable. ETT resistance increases when the ETT inner diameter is reduced. ${ }^{11}$ During the performance of flexible bronchoscopy through an ETT in patients receiving mechanical ventilation, air flow resistance across the ETT dramatically increases from 2- to 63 -fold. ${ }^{3}$ During PDT, whether using an ETT or laryngeal mask 


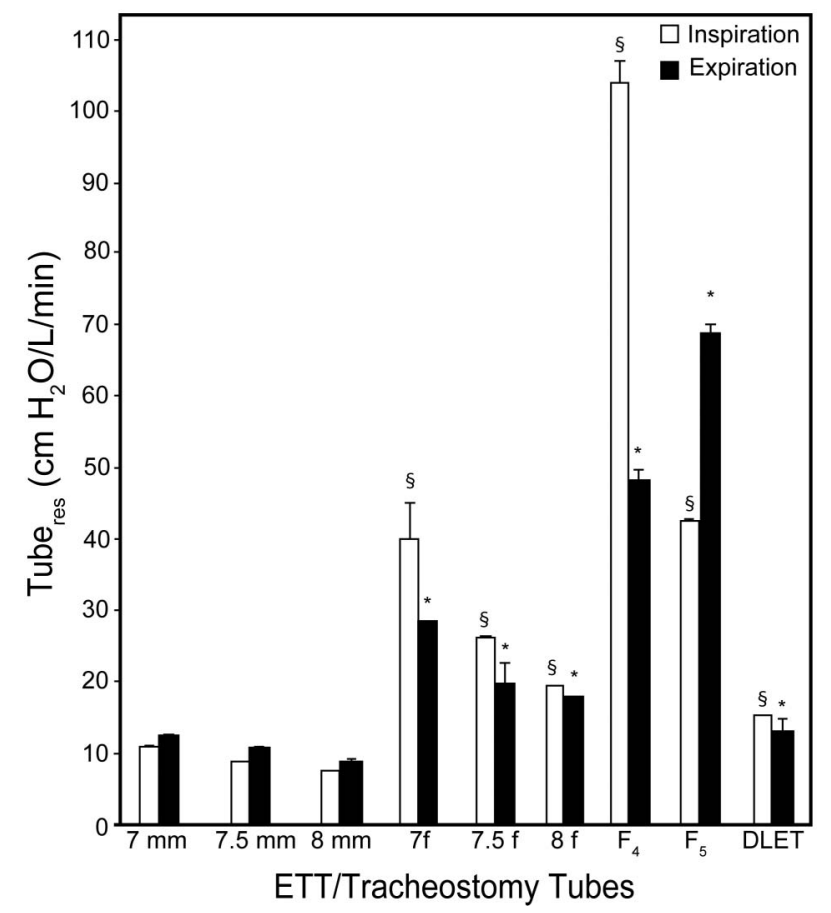

Fig. 4. Endotracheal tube resistance (Tube ${ }_{\text {res }}$ ) measured during the inspiratory and expiratory phases of volume controlled ventilation. Data are shown as median and interquartile range (error bars). * Statistical significance $(P<.05)$ for inspiratory resistance of the following comparisons: DLET vs $7 \mathrm{f}$, DLET vs $7.5 \mathrm{f}$, DLET vs $8 \mathrm{f}$, DLET vs $\mathrm{F}_{4}$, and DLET vs $\mathrm{F}_{5}$. $\S$ Statistical significance $(P<.05)$ for expiratory resistance of the following comparisons: DLET vs $7 \mathrm{f}$, DLET vs $7.5 f$, DLET vs $8 f$, DLET vs $F_{4}$, and DLET vs $F_{5}$. Tubes denoted with $\mathrm{mm}$ refer to the tube's inner diameter measurement; tubes denoted with $\mathrm{f}$ refer to tubes with a $4.5 \mathrm{~mm}$ external diameter fiberoptic bronchoscopy tube inserted; $F_{4}$ and $F_{5}$ refer to 4 and $5 \mathrm{~mm}$ inner diameter ventilation tubes, respectively; DLET refers to double lumen endotracheal tube, with $7.5 \mathrm{~mm}$ inner diameter.

airway, the airway resistance increases by introducing a fiberoptic bronchoscope, resulting in a decrease in minute ventilation and hypercapnia. ${ }^{2}$ According to Reilly et al, ${ }^{12}$ the use of fiberoptic bronchoscope during PDT is the most important factor responsible for the hypercapnia developed during the tracheostomy procedure. To minimize airway obstruction, it has been recommended to perform fiberoptic bronchoscopy through an ETT of $\geq 8 \mathrm{~mm}$ inner diameter, or with an ETT for which inner diameter is at least $2 \mathrm{~mm}$ larger than the external diameter of the bronchoscope. ${ }^{13}$ In our model of mechanical ventilation, although the size difference between ETT inner diameter and bronchoscope external diameter was $>2 \mathrm{~mm}$, the DLET had a lower inspiratory and expiratory resistance compared with ETTs with fiberoptic bronchoscope and translaryngeal airways. This is because the bronchoscopy is performed through a dedicated lumen without affecting the mechanical ventilation flow. The DLET, allowing ventilation independent from the use of fiberoptic bronchos- copy, may allow a more complete inspiration and expiration without imposing an excessive increase in airway resistance compared with the other devices commonly used for PDT.

Bronchoscope insertion through an ETT increases peak airway pressure in volume and pressure controlled ventilation, although the peak ventilator pressure does not accurately reflect the alveolar peak pressure. ${ }^{13,14}$ In our study, ventilator $\mathrm{P}_{\text {peak }}$ was higher in VC-CMV than in PC-CMV; however, DLET had the lowest $\mathrm{P}_{\text {peak }}$ regardless of ventilation mode during fiberoptic bronchoscopy.

$\mathrm{P}_{\text {mean }}$ is used to clinically assess mean alveolar pressure and is a major determinant of oxygenation and hemodynamic compromise during mechanical ventilation. ${ }^{15,16}$ Our data show that $\mathrm{P}_{\text {mean }}$ was higher in ETTs with bronchoscopy, and in $\mathrm{F}_{4}$ and $\mathrm{F}_{5}$ compared with DLET during VCCMV and PC-CMV.

PEEPi has been reported to increase by $105 \%$ after bronchoscope insertion, although this is not detected by ventilator sensors. ${ }^{13}$ The obstruction offered by the bronchoscope in the airway limits the expiratory and inspiratory flow resulting in volume trapped (incomplete exhalation) within the lung and increasing PEEPi. ${ }^{14}$ In a study by Lawson et al, ${ }^{14}$ at a compliance of $50 \mathrm{~mL} / \mathrm{cm} \mathrm{H}_{2} \mathrm{O}$, the insertion of a bronchoscope elevated the PEEPi from 0 to $6 \mathrm{~cm} \mathrm{H}_{2} \mathrm{O}$. In contrast, Lindholm et $\mathrm{al}^{17}$ reported that PEEPi increased dramatically when the bronchoscopy was performed through an ETT $<8 \mathrm{~mm}$ inner diameter. PEEPi may compromise ventilation and hemodynamics in critically ill patients, worsening gas exchange and reducing cardiac output. ${ }^{18}$ PEEPi with DLET was lower than with the other airway devices commonly used for tracheostomy in the ICU, but similar to ETTs without bronchoscopy. This finding suggests that DLET during tracheostomy for critically ill patients does not produce any increased expiratory obstruction to flow as with the other airway devices. It is possible to decrease PEEPi by a further reduction of minute ventilation, leading to hypercapnia and acute respiratory acidosis, which may be contraindicated in critically ill patients. ${ }^{12}$ The combination of DLET and reduction in minute ventilation can further decrease PEEPi, in cases of severe airway obstruction.

DLET may offer several clinical advantages over ETTs and laryngeal mask airways with bronchoscopy, during PDT. We hypothesize that using DLET during PDT (1) may ensure airway control avoiding the risk of accidental extubation and protection of the distal airway and lung parenchyma from bleeding and aspiration owing to the presence of a distal cuff and (2) may protect the fiberoptic bronchoscope from accidental damage as a result of puncture or inappropriate dilation by the presence of the upper tube. With the DLET in place, the posterior tracheal wall is protected during tracheal puncture. During the dilation and cannulation phase of PDT, the DLET should be with- 


\section{Double Lumen Endotracheal Tubes FOR PDT}

Table 3. Median Airway Measurements Across All Flow Settings in VC-CMV

\begin{tabular}{|c|c|c|c|c|c|c|c|c|c|c|c|c|c|c|c|c|}
\hline \multirow{2}{*}{$\begin{array}{c}\text { ETT/ } \\
\text { Tracheostomy } \\
\text { Tube }\end{array}$} & \multicolumn{4}{|c|}{ Inspiratory $\mathrm{P}_{\text {peak }}$} & \multicolumn{4}{|c|}{ Expiratory $\mathrm{P}_{\text {peak }}$} & \multicolumn{4}{|c|}{$P_{\text {mean }}$} & \multicolumn{4}{|c|}{ PEEPi } \\
\hline & Median & Q1 & Q3 & $P$ & Median & Q1 & Q3 & $P$ & Median & Q1 & Q3 & $P$ & Median & Q1 & Q3 & $P$ \\
\hline 7 & 28.36 & 28.03 & 29.01 & .01 & 18.44 & 18.41 & 18.57 & .002 & 11.81 & 11.77 & 11.87 & .46 & 5.10 & 5.08 & 5.15 & .87 \\
\hline 7.5 & 25.69 & 25.55 & 25.74 & .01 & 16.71 & 16.71 & 17.08 & .002 & 10.51 & 10.45 & 10.60 & .001 & 5.15 & 5.14 & 5.16 & $>.99$ \\
\hline 8 & 24.30 & 24.28 & 24.71 & .14 & 16.32 & 16.32 & 16.32 & .001 & 10.30 & 10.29 & 10.33 & .001 & 5.13 & 5.09 & 5.16 & $>.99$ \\
\hline $7 f$ & 36.85 & 36.82 & 36.98 & .001 & 17.89 & 17.75 & 17.94 & .002 & 14.85 & 14.74 & 14.92 & .001 & 9.07 & 9.04 & 9.12 & .03 \\
\hline $7.5 \mathrm{f}$ & 33.41 & 32.12 & 34.81 & .001 & 16.24 & 15.88 & 16.41 & .007 & 13.26 & 13.08 & 13.38 & .001 & 7.36 & 7.35 & 7.38 & .03 \\
\hline $8 \mathrm{f}$ & 32.98 & 32.64 & 33.71 & .001 & 17.33 & 17.33 & 17.66 & .002 & 12.67 & 12.64 & 12.83 & .001 & 6.19 & 6.13 & 6.28 & .03 \\
\hline $\mathrm{F}_{4}$ & 84.61 & 81.77 & 92.22 & .001 & 21.84 & 21.42 & 26.08 & .002 & 27.43 & 26.75 & 28.66 & .001 & 10.66 & 10.58 & 10.77 & .03 \\
\hline $\mathrm{F}_{5}$ & 41.24 & 41.04 & 41.39 & .001 & 16.59 & 15.33 & 17.52 & .006 & 13.86 & 13.82 & 13.91 & .001 & 7.23 & 7.22 & 7.25 & .03 \\
\hline DLET & 24.85 & 24.60 & 25.03 & NA & 14.69 & 14.68 & 15.05 & NA & 11.74 & 11.67 & 11.79 & NA & 5.15 & 5.13 & 5.01 & NA \\
\hline
\end{tabular}

Data have been reported as median and interquartile range. Inspiratory $\mathrm{P}_{\text {peak }}$, expiratory $\mathrm{P}_{\text {peak }}, \mathrm{P}_{\text {mean }}$, and PEEPi have been expressed as $\mathrm{cm} \mathrm{H}_{2} \mathrm{O}$

VC-CMV $=$ volume controlled continuous mandatory ventilation

$\mathrm{ETT}=$ endotracheal tube

$\mathrm{P}_{\text {peak }}=$ peak airway pressure

$\mathrm{P}_{\text {mean }}=$ mean airway pressure

PEEPi $=$ intrinsic PEEP

$\mathrm{Q}=$ quartile

7,7.5, and $8=7,7.5$, and $8 \mathrm{~mm}$ inner diameter endotracheal tubes

$7 \mathrm{f}, 7.5 \mathrm{f}$, and $8 \mathrm{f}=7,7.5$, and $8 \mathrm{~mm}$ inner diameter endotracheal tubes with $4.5 \mathrm{~mm}$ external diameter fiberoptic bronchoscope inserted into the endotracheal tube

$\mathrm{F}_{4}$ and $\mathrm{F}_{5}=4$ and $5 \mathrm{~mm}$ inner diameter ventilation tubes of a translaryngeal tracheostomy

DLET $=$ double lumen endotracheal tube

$\mathrm{NA}=$ no data available

Table 4. Median Airway Measurements Across All Flow Settings in PC-CMV

\begin{tabular}{|c|c|c|c|c|c|c|c|c|c|c|c|c|c|c|c|c|}
\hline \multirow{3}{*}{$\begin{array}{c}\text { ETT/ } \\
\text { Tracheostomy } \\
\text { Tube }\end{array}$} & \multicolumn{16}{|c|}{ PC-CMV } \\
\hline & \multicolumn{4}{|c|}{ Inspiratory $\mathrm{P}_{\text {peak }}$} & \multicolumn{4}{|c|}{ Expiratory $\mathrm{P}_{\text {peak }}$} & \multicolumn{4}{|c|}{$\mathrm{P}_{\text {mean }}$} & \multicolumn{4}{|c|}{ PEEPi } \\
\hline & Median & Q1 & Q3 & $P$ & Median & Q1 & Q3 & $P$ & Median & Q1 & Q3 & $P$ & Median & Q1 & Q3 & $P$ \\
\hline 7 & 20.90 & 18.91 & 21.27 & .27 & 15.46 & 15.42 & 16.90 & $>.99$ & 11.04 & 11.00 & 11.17 & .007 & 5.18 & 5.15 & 5.20 & $>.99$ \\
\hline 7.5 & 20.83 & 19.51 & 21.81 & .032 & 16.71 & 15.75 & 17.40 & .007 & 11.39 & 11.34 & 11.42 & .001 & 5.25 & 5.24 & 5.32 & .03 \\
\hline 8 & 20.68 & 20.01 & 21.70 & .02 & 15.67 & 14.54 & 16.71 & 1 & 11.51 & 11.41 & 11.88 & .001 & 5.20 & 5.15 & 5.23 & $>.99$ \\
\hline $7 f$ & 23.08 & 22.17 & 23.85 & .001 & 18.05 & 17.96 & 19.76 & .002 & 12.36 & 12.30 & 12.45 & .001 & 8.09 & 8.06 & 8.11 & .03 \\
\hline $7.5 \mathrm{f}$ & 22.97 & 21.82 & 23.25 & .001 & 17.38 & 17.32 & 18.82 & .002 & 11.92 & 11.81 & 11.94 & .001 & 6.74 & 6.54 & 6.94 & .03 \\
\hline $8 \mathrm{f}$ & 20.38 & 19.00 & 21.38 & .04 & 19.59 & 18.64 & 19.79 & .002 & 11.51 & 11.41 & 12.17 & .001 & 6.03 & 5.99 & 6.07 & .03 \\
\hline $\mathrm{F}_{4}$ & 28.42 & 27.68 & 28.89 & .001 & 20.24 & 20.18 & 22.61 & .002 & 16.15 & 16.00 & 16.34 & .001 & 9.56 & 9.49 & 9.59 & .03 \\
\hline $\mathrm{F}_{5}$ & 21.46 & 20.82 & 21.87 & .001 & 18.32 & 17.92 & 18.36 & .002 & 13.00 & 12.89 & 13.02 & .001 & 8.84 & 8.73 & 8.95 & .03 \\
\hline DLET & 18.23 & 18.10 & 18.40 & NA & 15.66 & 15.46 & 15.69 & NA & 10.88 & 10.73 & 10.96 & NA & 5.16 & 5.14 & 5.16 & NA \\
\hline \multicolumn{17}{|c|}{$\begin{array}{l}\text { Data have been reported as median and interquartile range. Inspiratory } \mathrm{P}_{\text {peak }} \text {, expiratory } \mathrm{P}_{\text {peak }}, \mathrm{P}_{\text {mean }} \text {, and PEEPi have been expressed as } \mathrm{cm} \mathrm{H}_{2} \mathrm{O} \text {. } \\
\text { VC-CMV }=\text { volume controlled continuous mandatory ventilation }\end{array}$} \\
\hline \multicolumn{17}{|c|}{ ETT $=$ endotracheal tube } \\
\hline \multicolumn{17}{|c|}{$\mathrm{P}_{\text {peak }}=$ peak airway pressure } \\
\hline \multicolumn{17}{|c|}{$\begin{array}{l}\mathrm{P}_{\text {mean }}=\text { mean airway pressure } \\
\mathrm{PEEPi}=\text { intrinsic PEEP }\end{array}$} \\
\hline \multicolumn{17}{|c|}{$\mathrm{Q}=$ quartile } \\
\hline \multicolumn{17}{|c|}{$7,7.5$, and $8=7,7.5$, and $8 \mathrm{~mm}$ inner diameter endotracheal tubes } \\
\hline \multicolumn{17}{|c|}{$7 \mathrm{f}, 7.5 \mathrm{f}$, and $8 \mathrm{f}=7,7.5$, and $8 \mathrm{~mm}$ inner diameter endotracheal tubes with $4.5 \mathrm{~mm}$ external diameter fiberoptic bronchoscope inserted into the endotracheal tube } \\
\hline \multirow{2}{*}{\multicolumn{17}{|c|}{$\begin{array}{l}\mathrm{F}_{4} \text { and } \mathrm{F}_{5}=4 \text { and } 5 \mathrm{~mm} \text { inner diameter ventilation tubes of a translaryngeal tracheostomy } \\
\text { DLET }=\text { double lumen endotracheal tube }\end{array}$}} \\
\hline & & & & & & & & & & & & & & & & \\
\hline $\mathrm{NA}=$ no data availi & & & & & & & & & & & & & & & & \\
\hline
\end{tabular}

drawn and positioned just cephlad of the site of puncture if the tracheal diameter is limited. However, in many patients, initial dilation can be accomplished with the DLET in place.
However, the use of the DLET implies an exchange of a preexisting ETT. In 2 surveys, it was reported that the ETT in place was replaced by $17 \%$ and $8 \%$ of respondents before PDT. ${ }^{19,20}$ During translaryngeal tracheostomy, pa- 


\section{Double Lumen Endotracheal Tubes for PDT}

tients are frequently intubated twice, first with the tracheoscope and then with a thin ventilation tube. ${ }^{21}$ We hypothesize that, in clinical practice, the replacement of the ETT with the DLET may be safely performed with an appropriate tube exchanger. Furthermore, the DLET should be carefully used in the presence of a difficult airway and in the presence of increased intracranial pressure.

The use of the DLET in a clinical setting of PDT remains to be studied; a clear strategic plan on when and how to use this device is required and should be evaluated further during an in vivo study.

\section{Limitations}

This study has limitations that need to be addressed. First, this is an in vitro evaluation of a DLET compared with other ETTs commonly used for tracheostomy, performed with an experimental model with single lung compliance. Second, because the model does not incorporate realistic airway resistance as in the lung, the increase in ventilator and airway pressures represents an overall increase of resistance as a result of the apparatus and is not reflected to the lower airway. Third, we did not test the DLET or other ETTs in vivo during actual airway management. As a result, we do not know the effect of the device on respiratory function and procedural comfort during actual PDT. The potential negative effects of reintubation and the impact of modification of the PDT technique should be investigated in future clinical studies.

\section{Conclusions}

The use of the DLET during PDT allows fiberoptic bronchoscopy without imposing an excessive increase in airway resistance. A reduced resistance to ventilation during a PDT may confer additional safety in a potentially hazardous procedure.

\section{REFERENCES}

1. Durbin GC Jr. Techniques for performing tracheostomy. Respir Care 2005;50(4):488-496.

2. Linstedt U, Möller F, Grote N, Zenz M, Prengel A. Intubating laryngeal mask as a ventilatory device during percutaneous dilatational tracheostomy: a descriptive study. Br J Anaesth 2007;99(6):912-915.

3. Hsia D, DiBlasi RM, Richardson P, Crotwell D, Debley J, Carter E. The effect of flexible bronchoscopy on mechanical ventilation in a paediatric lung model. Chest 2009;135(1):33-40.

4. Rohrer F. Der Strömungswiderstand in den menschlichen Atemwegen und der Einflu $\beta$ der unregelmässigen Verzweigung des Bronchialsystems auf den Atmungsverlauf in den verschiedenen Lungen- bezirken. Pfluegers Arch Gesamte Physiol Menschen Tiere 1915; 162:225-299.

5. Lichtwarck-Aschoff M, Helmer A, Kawati R, Lattuada M, Sjöstrand $\mathrm{UH}$, Zügel N, et al. Good short-term agreement between measured and calculated tracheal pressure. Br J Anaesth 2003;91(2):239-248.

6. Haberthür C, Lichtwarck-Aschoff M, Guttmann J. Continuous monitoring of tracheal pressure including spot-check of endotracheal tube resistance. Technol Health Care 2003;11(6):413-424.

7. Flevari AG, Maniatis N, Kremiotis TE, Siempos I, Betrosian AP, Roussos C, et al. Rohrer's constant, K2, as a factor of determining inspiratory resistance of common adult endotracheal tubes. Anaesth Intensive Care 2011;39(3):410-417.

8. Ferraro F, Capasso A, Troise E, Lanza S, Azan G, Rispoli F, Anello $\mathrm{CB}$. Assessment of ventilation during the performance of elective endoscopic-guided percutaneous tracheostomy. Chest 2004;126(1): 159-164.

9. Wilson AM, Gray DM, Thomas JG. Increases in endotracheal tube resistance are unpredictable relative to duration of intubation. Chest 2009;136(4):1006-1013

10. Campos JH. Update on tracheobronchial anatomy and flexible fiberoptic bronchoscopy in thoracic anesthesia. Curr Opin Anaesthesiol 2009;22(1):4-10.

11. El-Khatib MF, Husari A, Jamaleddine GW, Ayoub CM, Bou-Khalil P. Changes in resistance tubes with reductions in cross-sectional area. Eur J Anaesthesiol 2008;25(4):275-279.

12. Reilly PM, Sing RF, Giberson FA, Anderson HL 3rd, Rotondo MF, Tinkoff GH, Schwab CW. Hypercarbia during tracheostomy: a comparison of percutaneous endoscopic, percutaneous Doppler and standard surgical tracheostomy. Intensive Care Med 1997;23(8):859864.

13. Nakstad ER, Opdahl H, Skjønsberg OH, Borchsenius F. Intrabronchial airway pressures in intubated patients during bronchoscopy under volume controlled and pressure controlled ventilation. Anaesth Intensive Care 2011;39(3):431-439.

14. Lawson RW, Peters JI, Shelledy DC. Effects of fiberoptic bronchoscopy during mechanical ventilation in a lung model. Chest 2000; 118(3):824-831.

15. Boros SJ. Variations in inspiratory:expiratory ratio and airway pressure wave form during mechanical ventilation: the significance of mean airway pressure. J Pediatr 1979;94(1):114-117.

16. Marini JJ, Ravenscraft SA. Mean airway pressure: physiologic determinants and clinical importance, part 1. Crit Care Med 1992; 20(10):1461-1472.

17. Lindholm CE, Ollman B, Snyder JV, Millen EG, Grenvik A. Cardiorespiratory effects of flexible fiberoptic bronchoscopy in critically ill patients. Chest 1978;74(4):362-368.

18. Mughal MM, Culver DA, Minai OA, Arrolinga AC. Auto-positive end-expiratory pressure: mechanics and treatment. Cleve Clin J Med 2005;72(9):801-809.

19. Vargas M, Servillo G, Arditi E, Brunetti I, Pecunia L, Salami D, et al. Tracheostomy in intensive care unit: a national survey in Italy. Minerva Anestesiol 2013;79(2):156-164.

20. Veenith T, Ganeshamoorthy S, Standley T, Carter J, Young P. Intensive care unit tracheostomy: a snapshot of UK practice. Int Arch Med 2008;1(1):21-27.

21. Fantoni A, Ripamonti D. A non-derivative, non-surgical tracheostomy: the translaryngeal method. Intensive Care Med 1997;23(4): 386-392. 